\title{
International mobility, sexual behaviour and HIV-related characteristics of men who have sex with men residing in Belgium
}

\author{
Wim Vanden Berghe ${ }^{1 *}$, Christiana Nöstlinger ${ }^{1}$, Harm Hospers $^{2}$ and Marie Laga ${ }^{1}$
}

\begin{abstract}
Background: European men who have sex with men (MSM) continue to be disproportionally affected by the human immunodeficiency virus (HIV). Several factors are contributing to the rates of new HIV infections among MSM. The aim of this study was to investigate the potential role of travel behaviour and sexual mobility in the spread of HIV and sexually transmitted infections (STI) among European MSM.
\end{abstract}

Methods: Belgian data from the first pan-European MSM internet survey EMIS was used ( $n=3860$ ) to explore individual and contextual determinants of sexual behaviour among MSM, who resided in Belgium at the time of data collection and who reported having had sexual contact abroad in the last 12 months. Descriptive and bivariate analyses were performed. Odds ratios and 95\% confidence intervals were calculated by means of logistic regression.

Results: MSM who practiced unprotected anal intercourse UAI during their last sexual encounter abroad were less likely to be living in a large city (OR:0.62, 95\% Cl:0.45-0,86, p<0.01) and more likely to be HIV positive (OR:6.20, 95\% Cl:4.23-9.06, $\mathrm{p}<0.001)$ ), to have tested HIV positive in the last 12 months (OR:3.07, 95\% Cl:1.07-8.80, $\mathrm{p}<0.05)$, to have been diagnosed with any STI in the last 12 months (OR:2.55; 95\% Cl:1.77-3.67, $\mathrm{p}<0.05$ ), to have used party drugs (OR:2.22, 95\% Cl:1.59-3.09, $\mathrm{p}<0.001$ ), poppers (OR:1.52, 95\% Cl:1.07-2.14, $\mathrm{p}<0.001)$ and erection enhancing substances (OR:2.23, 95\% Cl:1.61-3.09, p<0.001) compared to MSM who did not have UAl with their last sexual partner abroad. Men having had UAI in the last 12 months were more likely to have done so in a neighbouring country of Belgium (OR:1.66, 95\% Cl:1.21-2.29, p<0.001). Different sexual behavioural patterns related to condom use and drug use were identified according to HIV test status among travelling men.

Conclusions: The results of this study provide evidence for the role of international mobility and sexual behavior while travelling, in the spread of HIV and STI among MSM in Europe. Further, the findings underline the need for development of European cross-border HIV and STI interventions with coherent messages and prevention policies for MSM.

Keywords: HIV infection, Men who have sex with Men (MSM), Travel

\section{Background}

The human immunodeficiency virus (HIV) continues to disproportionally affect men who have sex with men (MSM), an epidemic that remains a challenge for European public health. In most Western European countries, including Belgium, the number of yearly diagnoses of new HIV infections in MSM remains high [1,2]. Several factors are contributing to the rates of new HIV infections among

\footnotetext{
* Correspondence: wvandenberghe@itg.be

'Department of Public Health, Institute of Tropical Medicine HIV/AIDS Center (IHAC), Antwerp, Belgium

Full list of author information is available at the end of the article
}

MSM, including an increase in sexual risk behaviour, combined with a high prevalence of HIV infection in some networks of MSM [3-5]. It has also been suggested that travel behaviour and sexual mobility could potentially be a factor in the spread of HIV and sexually transmitted infections (STI) among European MSM [1,4]. Travelling has been considered an important component of gay lifestyle and identity, as gay men travel to destinations where they can socialize with peers and in some cases avoid the social constraints and intolerance of their home environments [6]. For some gay men, social and sexual networking are highly intertwined and sexual

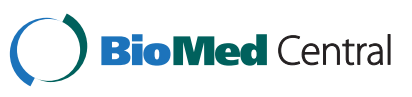


identity is a central factor for some gay men in deciding on the travel destination [7]. Furthermore, globalization and European integration have resulted in shifts in travel decision making, among other reasons because of cheaper flights, which made gay men and other MSM even more internationally mobile than before. These processes have not developed to the same extent across Europe, and some countries have a different general tourism profile than others $[8,9]$. At European level, most Western European countries have been at the international forefront in implementing legal equality and anti-discrimination laws for lesbians, gays, bisexuals and transgenders (LGBT). In this changing context, some bigger cities such as Barcelona (ES), Berlin (DE) or Paris (FR), but also Antwerp (BE) have invested in- and attracted more LGBT tourism by means of different social marketing strategies. These cities offer a diverse mixture of cultural and festive experiences directed at sexual minorities and especially MSM, mirroring the diversity of gay subculture. These efforts seem to influence the choice of travel destination for MSM. For instance, results from the recent European MSM Internet study (EMIS) showed that Spain, Germany and France were the countries to which the majority of MSM traveled $[10,11]$. The factors above may explain the higher probability of finding more gay men and in a broader sense, MSM, in a given travel destination.

There is a need to better understand the dynamics that are at the basis of the European HIV/STI epidemics among MSM, particularly how sexual networks across countries may contribute to the current HIV epidemic among European MSM. Different United States-based studies showed that, in the context of recreational travel, MSM reported specific patterns of unprotected anal intercourse (UAI) and related substance use [12,13]. However, limited attention has been paid thus far to investigate sexual behaviour of European gay men while travelling. The present study aims at filling this gap by analysing HIV-related individual- and contextual characteristics of MSM residing in Belgium travelling abroad. Belgium functions here as a case study for sexual behaviour among mobile MSM in the European context. We use data from the first pan-European MSM internet survey EMIS to explore individual and contextual determinants of sexual behaviour among MSM who were residing in Belgium at the time of data collection and who reported having had sexual contact abroad in the preceding 12 months.

\section{Methods}

Dataset

The European MSM Internet survey recruited participants from June up to and including August 2010. MSM from 38 different European countries, including the 27
EU Member States, completed an online questionnaire on sexual health, which was presented in 25 languages. An offline- and online recruitment campaign, with the support of many LGBT organizations across all countries, preceded the data collection to motivate respondents to participate. The use and support of gay social online networks Gayromeo, Manhunt, Qruiser, Qguys and Gaydar were instrumental in reaching the target population. In total 174209 MSM participated in the EMIS study. Respondents completed the questionnaire in an average time of 20 minutes. More information and on the EMIS project and its methodology and descriptive results can be found on www.EMIS-project.eu, in a number of publications [14-16] and in the EMIS final report [11]. The EMIS study was approved by the Research Ethics Committee of the University of Portsmouth, UK (REC application number 08/09:21).

\section{Measures \\ Background characteristics}

Respondents reported on their age, education, sexual identity, level of urbanization (i.e. living in a city with more than 500.000 inhabitants), occupation, nationality, EMIS expat- (living in one of the 38 EMIS countries but not in the country of birth) and relationship status.

\section{Sexual and HIV/STI related behaviour, drug use and health aspects in the last 12 months}

With regards to sexual practices, we assessed whether participants had anal sex and if so, whether condoms were used with casual and steady partners during 12 months before the EMIS study. We refer to anal sex without the use of condoms as unprotected anal intercourse or UAI. We assessed perceived seroconcordant UAI with a casual partner in the last 12 months. The participants also reported on HIV and STI testing behaviour (Syphilis, Gonorrhea, Chlamydia, anal/genital warts, anal/genital herpes, Hepatitis B and C) and diagnoses during the last 12 months, the current HIV serostatus, the number of non-steady sex partners. We assessed recreational drugs typically associated with sex and parties referring to them in this paper as party drugs (XTC, amphetamine, crystal, mephedrone, GHB, ketamine, cocaine), poppers, and erectile enhancing medication use. HIV positive participants reported whether they were taking antiretroviral treatment (ART) and their HIV viral load during their last check-up.

\section{Sexual contact abroad}

Respondents reported whether they have had any sexual contact with casual partners abroad in the last 12 months. Subsequently, more detailed questions were asked related to the last sexual contact abroad: country in which it took place; how and where the sexual partner was met, 
whether they engaged in anal sex and if so, whether condoms were used.

\section{Statistics}

Data analysis was performed using IBM SPSS statistics version 20. To assess differences in proportions and means, according to having had sex abroad, Mann-Whitney U-tests were performed for continuous variables, and chi squares were calculated for categorical variables. Univariate and multivariate logistic regression was used to calculate odds ratios and 95\% confidence intervals for the different background, risk and contextual factors comparing MSM on the basis of having had sex abroad in the last 12 months and having performed UAI during the last sexual encounter abroad. Adding variables to the model for the multivariate analysis was based on significance of the univariate analyses. Differences in proportions and means between three different groups (i.e. HIV positive, HIV negative, and untested men) on the basis of self-reported HIV-status were tested for statistical significance using analysis of variance (ANOVA) and Tukey's post-hoc test.

\section{Results}

Description of the total sample of MSM residing in Belgium The total EMIS sample of MSM residing in Belgium comprised 3982 men. We excluded 84 participants who said they never had sex with another man and 38 men who did not answer the questions on sexual contact abroad. The total number of eligible men for analysis was 3860 (Table 1). Mean age was 35.2 (SD:11.4) years old. Of Belgian resident MSM, 64.6\% (n:2493) were higher educated, $5.2 \%$ (n:200) were unemployed and $45.5 \%$ (n:1758) were in a steady relationship. A total of 955 (24.7\%) men were expatriates and 43.3\% (n:1674) resided in a large city. Concerning sexual identity, $85.4 \%$ (n:3298) reported to identify as homosexual, 9\% (n:348) as bisexual. During the last 12 months, 85\% (n:3281) of respondents reported having had anal sex, 39.2\% (n:1514) had UAI with a steady partner and $25.7 \%$ (n:993) had UAI with casual partner(s). Overall, 43.7\% ( $\mathrm{n}: 1688)$ of MSM had an HIV test in the last 12 months and $10.4 \%$ (n:332) reported being HIV positive. A total of $1562(40.5 \%)$ respondents had been tested for STI in the last 12 months and the most frequently reported STI were Syphilis (7.7\%, n:121), Gonorrhea (8.8\%, n:137) and Chlamydia (8.3\%, n:130). For all respondents, substance use in the last 12 months included consuming party drugs $(17.7 \%, \mathrm{n}: 683)$, poppers $(38.9 \%, \mathrm{n}: 1500)$ and erectile enhancers $(19.5 \%, \mathrm{n}: 751)$. Of central interest to this study is that $39.1 \%$ (n:1510) of Belgian resident MSM reported having had sexual contact abroad with a casual partner in the last 12 months. We will refer to this group of MSM as "sexually mobile men".

\section{MSM residing in Belgium}

\section{Differences according to having had sexual contact abroad} in the last 12 months

Table 1 displays the bivariate analysis of the different background, sexual risk and contextual characteristics of MSM residing in Belgium according to having had sex abroad with a casual partner in the last 12 months. Significant differences are reported between sexually mobile MSM, compared to those men residing in Belgium, who did not have sex abroad. Sexually mobile men were on average significantly older ( 37.2 vs. 34.2 years old, $\mathrm{p}<0.001)$, had a higher education $(71.3 \%$ vs. $60.3 \%$, $\mathrm{p}<0.001$ ), were more often living in Belgium as an expatriate $(38.5 \%$ vs. $15.9 \%, \mathrm{p}<0.001)$, and resided more often in a large city ( $54.8 \%$ vs. $36 \%, p<0.001)$, compared to men who did not have sex abroad. Also, sexually mobile men identified more often as homosexual or gay $(89.0 \%$ vs. $83.1 \%, \mathrm{p}<0.001)$ and less often as bisexual $(6.1 \%$ vs. $10.9 \%$, p $<0.001)$. Further, HIV testing ( $47.5 \%$ vs. $41.3 \%$, $\mathrm{p}<0.001)$ and STI testing (53.3\% vs. $32.2 \%, \mathrm{p}<0.001)$ in the last 12 months was more often reported and a higher percentage of sexually mobile men were HIV positive (15.2\% vs. $6.8 \%, \mathrm{p}<0.001)$. Higher numbers of diagnoses of Syphilis (9.3\% vs. 6.1\%, $\mathrm{p}<0.001)$, Gonorrhea $(11.4 \%$ vs. $5.9 \%, \mathrm{p}<0.001)$, Chlamydia $(11.8 \%$ vs. $4.6 \%, \mathrm{p}<0.001)$ ), anal/genital warts $(6.7 \%$ vs. $5.8 \%, \mathrm{p}<0.01)$, current infection of hepatitis $\mathrm{C}(2 \%$ vs. $1.5 \%, \mathrm{p}<0.05)$ during the last 12 months and lifetime infection of hepatitis $B$ $(19 \%$ vs. $18 \%, p<0.001)$ were reported by sexually mobile men compared to men who did not have sex abroad. Sexually mobile men more often had anal sex $(93.1 \%$ vs. $79.1 \%, \mathrm{p}<0.001)$ and more unprotected anal sex with casual partner(s) $(36.5 \%$ vs. $18.6 \%, \mathrm{p}<0.001)$ in the last 12 months. They also had a higher number of non-steady sex partners in the last 12 months (11 to 20 vs. 2 partners, $\mathrm{p}<0.001)$, used more party drugs $(26.9 \%$ vs. $11.8, \mathrm{p}<0.001)$, poppers $(56.3 \%$ vs. $27.7 \%, \mathrm{p}<0.001)$ and erection enhancing substances $(30.8 \%$ vs. $12.2 \%, \mathrm{p}<0.001)$ in the last 12 months compared to Belgian resident MSM who did not have any sexual contact abroad. Countries, where a majority of sexually mobile men had sexual contacts during the last 12 months included France (18.1\%), Spain (15.7\%), Germany (10.6\%) and The Netherlands (9.1\%).

\section{Determinants of UAI during the last sexual encounter abroad among sexually mobile men}

Table 2 shows the results of univariate and multivariate logistic analyses with UAI during the last sexual encounter abroad as the dependent variable. Sexually mobile men, who practiced UAI during their last sexual encounter abroad were less likely to be living in a large city (OR:0.62, 95\% CI:0.45-0,86, $\mathrm{p}<0.01)$ and more likely to be HIV positive (OR:6.20, 95\% CI:4.23-9.06, $\mathrm{p}<0.001$ )), to have been diagnosed HIV positive in the last 12 months 
Table 1 Hiv related individual and contextual characteristics of MSM residing in Belgium according to having had sexual contact abroad in the last 12 months

\begin{tabular}{|c|c|c|c|c|c|c|c|c|}
\hline & \multicolumn{6}{|c|}{ MSM residing in Belgium - Sexual contact abroad? } & \multirow{2}{*}{$\begin{array}{l}\text { Test } \\
\text { statistic* }\end{array}$} & \multirow{2}{*}{$\begin{array}{l}P \\
\text { value }\end{array}$} \\
\hline & Total (N:3860) & $\%$ & Yes (N:1510) & $\%$ & No (N:2350) & $\%$ & & \\
\hline Age (mean(SD)) & 3860 & $\begin{array}{l}35,2 \\
(11,4)\end{array}$ & 1510 & $\begin{array}{l}37,2 \\
(10,33)\end{array}$ & 2350 & $\begin{array}{l}34,2 \\
(12,1)\end{array}$ & 62,408 & $<0,001$ \\
\hline Higher education & 2493 & 64,6 & 1077 & 71,3 & 1416 & 60,3 & 82,306 & $<0,001$ \\
\hline Unemployment rate & 200 & 5,2 & 70 & 4,6 & 130 & 5,5 & 10,426 & 0,001 \\
\hline Steady relationship & 1758 & 45,5 & 669 & 44,3 & 1089 & 46,3 & 0,04 & 0,433 \\
\hline Expatriate & 955 & 24,7 & 581 & 38,5 & 374 & 15,9 & 251,325 & $<0,001$ \\
\hline Living in a large city (>500.000 inh.) & 1674 & 43,4 & 828 & 54,8 & 846 & 36 & 140,557 & $<0,001$ \\
\hline Sexual identity - Homosexual & 3298 & 85,4 & 1344 & 89 & 1954 & 83,1 & 26,129 & $<0,001$ \\
\hline Sexual identity - Bisexual & 348 & 9 & 92 & 6,1 & 256 & 10,9 & 25,77 & $<0,001$ \\
\hline Anal sex last $12 \mathrm{~m}$ & 3281 & 85 & 1406 & 93,1 & 1860 & 79,1 & 145,244 & $<0,001$ \\
\hline UAI Steady partner last $12 \mathrm{~m}$ & 1514 & 39,2 & 5703 & 37,7 & 940 & 40 & 2,265 & 0,072 \\
\hline UAI Casual partner last $12 \mathrm{~m}$ & 993 & 25,7 & 551 & 36,5 & 437 & 18,6 & 32,812 & $<0,001$ \\
\hline $\begin{array}{l}\text { Nr of casual partners last } 12 \mathrm{~m} \\
\text { (median category) }\end{array}$ & & 4 & & 11 to 20 & & 2 & 1227,601 & $<0,001$ \\
\hline Hiv test last $12 \mathrm{~m}$ & 1688 & 43,7 & 718 & 47,5 & 970 & 41,3 & 48,445 & $<0,001$ \\
\hline Hiv status - positive (among tested) & 332 & 10,4 & 210 & 15,2 & 122 & 6,8 & 58,433 & $<0,001$ \\
\hline STI test last $12 \mathrm{~m}$ & 1562 & 40,5 & 805 & 53,3 & 757 & 32,2 & 96,565 & $<0,001$ \\
\hline \multicolumn{9}{|l|}{$\begin{array}{l}\text { STI history last } 12 \mathrm{~m} \\
\text { (among tested for any STI) }\end{array}$} \\
\hline Syphilis & 121 & 7,7 & 75 & 9,3 & 46 & 6,1 & 27,299 & $<0,001$ \\
\hline Gonorrhoea & 137 & 8,8 & 92 & 11,4 & 45 & 5,9 & 46,995 & $<0,001$ \\
\hline Chlamydia & 130 & 8,3 & 95 & 11,8 & 35 & 4,6 & 65,283 & $<0,001$ \\
\hline Anal/genital warts & 98 & 6,3 & 54 & 6,7 & 44 & 5,8 & 10,92 & 0,001 \\
\hline Anal/genital herpes & 42 & 2,7 & 22 & 2,7 & 20 & 2,6 & 3,135 & 0,055 \\
\hline Hepatitis C 12 m & 10 & 0,6 & 6 & 0,7 & 4 & 0,5 & 1,839 & 0,152 \\
\hline Hepatitis C current & 27 & 1,7 & 16 & 2,0 & 11 & 1,5 & 4,638 & 0,027 \\
\hline Hepatitis B (ever) & 289 & 18,5 & 153 & 19,0 & 136 & 18,0 & 25,05 & 0,001 \\
\hline \multicolumn{9}{|l|}{ Drug use last $12 \mathrm{~m}$} \\
\hline Party drugs & 683 & 17,7 & 407 & 26,9 & 276 & 11,8 & 146,085 & 0,001 \\
\hline Poppers & 1500 & 38,9 & 850 & 56,3 & 650 & 27,7 & 179,881 & 0,001 \\
\hline Erectile enhancers & 751 & 19,5 & 465 & 30,8 & 286 & 12,2 & 202,213 & 0,001 \\
\hline $\begin{array}{l}\text { Anal sex during last sexual contact } \\
\text { abroad }\end{array}$ & & & 859 & 56,8 & & & & \\
\hline UAI during last sexual contact abroad & & & 219 & 14,5 & & & & \\
\hline \multicolumn{9}{|l|}{ Country of last sexual contact abroad } \\
\hline The Netherlands & & & 137 & 9,1 & & & & \\
\hline Germany & & & 161 & 10,6 & & & & \\
\hline France & & & 272 & 18,1 & & & & \\
\hline UK & & & 74 & 4,9 & & & & \\
\hline Spain & & & 237 & 15,7 & & & & \\
\hline
\end{tabular}

*Test statistics: $\mathrm{U}$ value for continuous variables. $\mathrm{x} 2$ for categorical variables.

**p values: Mann-Whitney $\mathrm{U}$ test for continuous variables and $\mathrm{X} 2$ for categorical variables. 
Table 2 Univariate and multivariate logistic regression with unprotected anal intercourse during the last sexual encounter of MSM residing in Belgium as the dependent variable

\begin{tabular}{|c|c|c|c|c|c|c|c|c|}
\hline \multirow[b]{4}{*}{ Age $>=30$ years old } & \multicolumn{8}{|c|}{ UAI during last sexual encounter abroad } \\
\hline & \multicolumn{4}{|c|}{ Univariate } & \multicolumn{4}{|c|}{ Multivariate } \\
\hline & \multirow{2}{*}{$\begin{array}{l}\mathbf{P} \\
0,940\end{array}$} & \multirow{2}{*}{$\begin{array}{l}\text { OR } \\
1,01\end{array}$} & \multicolumn{2}{|c|}{$95 \% \mathrm{Cl}$} & \multirow[t]{2}{*}{$P$} & \multirow[t]{2}{*}{ OR } & \multicolumn{2}{|c|}{$95 \% \mathrm{Cl}$} \\
\hline & & & 0,71 & 1,44 & & & & \\
\hline Higher education & 0,153 & 0,77 & 0,54 & 1,10 & & & & \\
\hline Steady relationship & 0,208 & 1,23 & 0,89 & 1,69 & & & & \\
\hline Expatriate & 0,480 & 0,89 & 0,64 & 1,24 & & & & \\
\hline Living in a large city (>500000 inh.) & 0,004 & 0,62 & 0,45 & 0,86 & 0,041 & 0,67 & 0,46 & 0,98 \\
\hline Diagnosed HIV positive last $12 \mathrm{~m}$ & 0,036 & 3,07 & 1,07 & 8,81 & & & & \\
\hline Diagnosed with any STI last $12 \mathrm{~m}$ & $<0,001$ & 2,55 & 1,77 & 3,68 & 0,019 & 1,76 & 1,10 & 2,83 \\
\hline Hiv status - positive & 0,001 & 6,20 & 4,24 & 9,07 & 0,009 & 3,88 & 1,41 & 10,67 \\
\hline \multicolumn{9}{|c|}{ Number of non- steady partners last $12 \mathrm{~m}$ (1 to 5 ) } \\
\hline 6 to 20 & 0,345 & 0,81 & 0,53 & 1,25 & & & & \\
\hline $20+$ & 0,306 & 1,24 & 0,82 & 1,87 & & & & \\
\hline Party drugs & $<0,001$ & 2,22 & 1,60 & 3,10 & 0,912 & 1,03 & 0,63 & 1,69 \\
\hline Poppers & $<0,001$ & 1,52 & 1,08 & 2,14 & 0,632 & 0,90 & 0,60 & 1,36 \\
\hline Erectile enhancers & $<0,001$ & 2,23 & 1,61 & 3,09 & 0,757 & 1,07 & 0,69 & 1,68 \\
\hline Sexual contact in neighbouring country & $<0,001$ & 1,67 & 1,21 & 2,30 & 0,711 & 1,08 & 0,73 & 1,59 \\
\hline \multicolumn{9}{|l|}{ Meeting place for last sexual contact abroad } \\
\hline Website & 0,321 & 0,85 & 0,62 & 1,17 & & & & \\
\hline Gay bar/disco/nightclub & 0,923 & 1,02 & 0,67 & 1,55 & & & & \\
\hline Sex club/darkroom/gay sauna & 0,701 & 1,07 & 0,77 & 1,47 & & & & \\
\hline
\end{tabular}

(OR:3.07, 95\% CI:1.07-8.80, $\mathrm{p}<0.05$ ), to have been diagnosed with any STI in the last 12 months (OR:2.55; 95\% $\mathrm{CI}: 1.77-3.67, \mathrm{p}<0.05)$, to have used party drugs (OR:2.22, 95\% CI:1.59-3.09, $\mathrm{p}<0.001)$, poppers (OR:1.52, 95\% $\mathrm{CI}: 1.07-2.14, \mathrm{p}<0.001)$ and erection enhancing substances (OR:2.23, 95\% CI:1.61-3.09, $\mathrm{p}<0.001$ ), compared to MSM who did not have UAI with their last sexual partner abroad. Men having had UAI in the last 12 months were more likely to have done so in a neighbouring country of Belgium (OR:1.66, 95\% CI:1.21-2.29, p<0.001).

Multivariate analysis with MSM having had UAI abroad as the dependent variable showed that, when controlling for variables significant in the univariate models, the odds for having had UAI during the last sexual encounter abroad were 3,88 times higher for HIV positive men (95\% CI:1.14-10.67, $\mathrm{p}<0.01), 1.76$ higher for men, diagnosed with any STI in the last 12 months (95\% CI:1.1-2.83, $\mathrm{p}<0.05)$ and 0.67 lower for men, residing in a large city (95\% CI:0.46-0.98, p<0.05)

Sexual behaviour, drug use and STI history in the last 12 months according to HIV test status among sexually mobile men

Table 3 shows characteristics of the last sexual contact abroad according to participants' HIV test status. Of the HIV positive men, $62 \%$ were on ART and $57 \%$ had an undetectable viral load. HIV positive men reported significantly more often to have had unprotected sex with a casual partner ( 73.9 vs. $34 \%$ vs. $27.1 \%$, p $<0.001)$, practiced more seroconcordant UAI with a casual partner in the last 12 months $(52.8 \%$ vs. $15.8 \%$ vs. $12.9 \%, \mathrm{p}<0.001)$ and had a higher number of casual sex partners during the last 12 months than HIV negative and untested men (more than 50 vs. 11 to 20 partners, $\mathrm{p}<0.001$ ). Concerning STI history, HIV positive men reported significantly more Syphilis $(43.9 \%$ vs. $18.8 \%$ vs. $8.3 \%, \mathrm{p}<0.001)$ and Chlamydia (19.7\% vs. $4.3 \%$ vs. $3.4 \%$ ) during the last 12 months and more current infections of Hepatitis C (14.6\% vs. $1.9 \%$ vs. $8.3 \%), \mathrm{p}<0.001)$; than HIV negative and untested men. Party drugs $(62.7 \%$ vs. $22.2 \%$ vs. $12.9 \%, \mathrm{p}<0.001)$, poppers (62.7 vs. $26.6 \%$ vs. $13.8 \%)$ and erection enhancing substances $(79.8 \%$ vs. $54.2 \%$ vs. $33.6 \%)$ were used significantly more often by HIV positive men than by HIV negative and untested men.

\section{Characteristics of the last sexual encounter abroad} according to HIV test status among sexually mobile men HIV-positive men reported higher numbers of anal sex ( $82.9 \%$ vs. $56.1 \%$; $59.5 \%, \mathrm{p}<0.001$ ) and also more occasions of unprotected anal sex than HIV negative and untested 
Table 3 Background and HIV-related characteristics according to HIV test status among mobile MSM residing in Belgium*

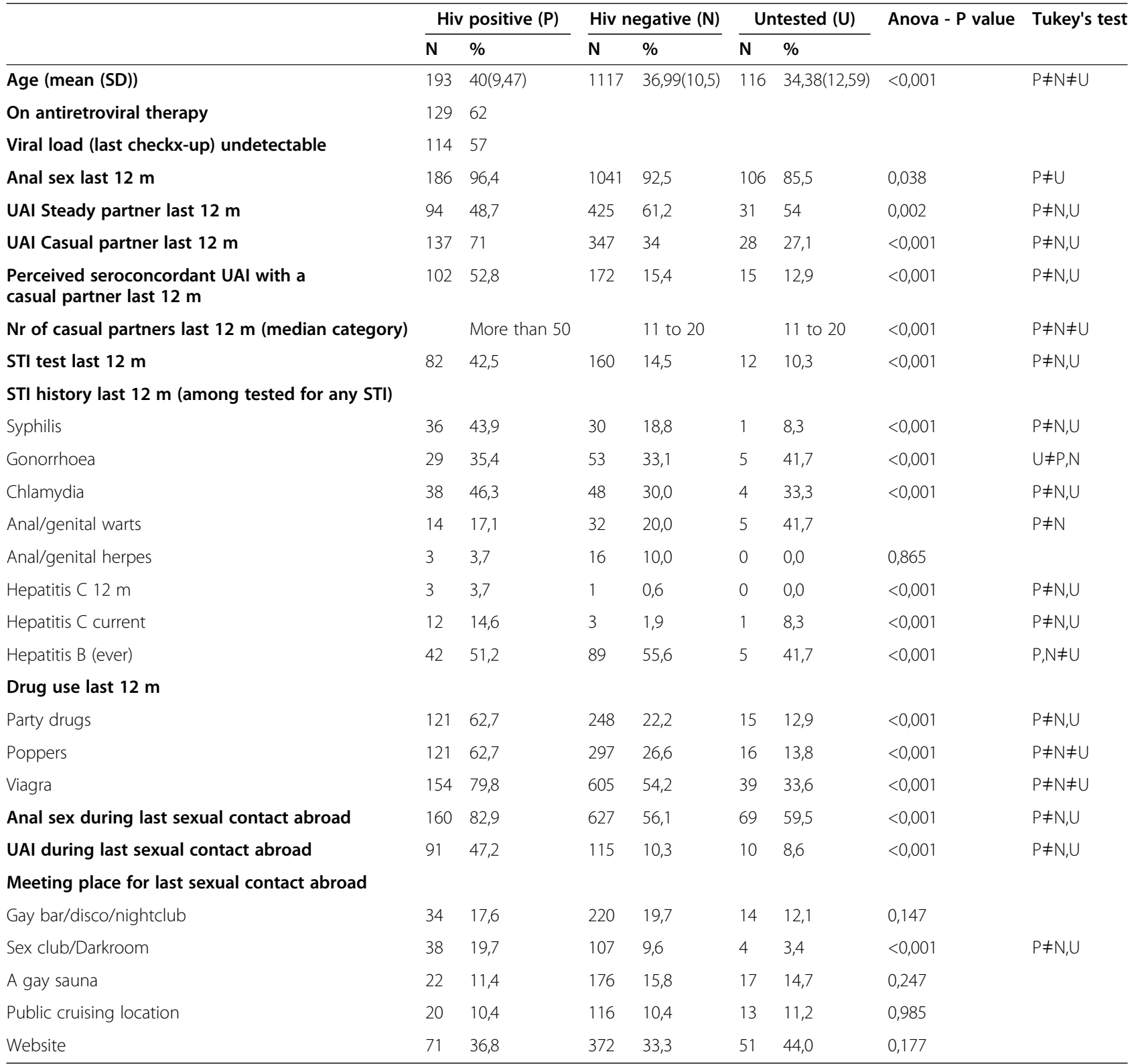

*Total $\mathrm{n}$ for sexual contact abroad among MSM residing in Belgium = 1510 (may differ due to missing values on HIV test status).

men (47.2\% vs. $10.3 \%$; $8.6 \%$, $\mathrm{p}<0.001)$. HIV positive men also met their last sex partner abroad significantly more often in sex clubs and darkrooms (19.7\% vs. 9.6\%; $3.4 \%$, $\mathrm{p}<0.001)$ than their HIV-negative or untested counterparts.

\section{Discussion}

The present study used data from the European Internet MSM Survey (EMIS) to investigate sexual behaviour of MSM who were sexually active when travelling abroad in the last 12 months prior to the survey. Our results for the case of Belgium show that HIV and STI are highly prevalent among travelling MSM, and that they adopt more sexual risk behaviours than MSM who were not sexually active abroad. This evidence supports cross-border development of prevention activities for HIV and STI among MSM.

MSM residing in Belgium who had sexual contact abroad were more likely to be expatriates and to be living in a bigger city. This finding can probably be explained by the substantial population of expatriates living in Brussels and working at its many European and international institutions. Belgian resident MSM having had sex abroad were also better educated and on average older than their counterparts who did not report any sexual activity abroad. Being able to travel implies disposable income to 
do so. Similar results were found in a study on gay resorts [17]. This study also demonstrates that sexual identity does play a role in travel behaviour as was suggested in other studies $[6,10,18]$. Significantly more sexually mobile MSM identified as homosexual or gay and less often as bisexual. The majority of MSM residing in Belgium who had sex abroad mostly did so in Belgium's neighboring countries: Germany, France, The Netherlands and the United Kingdom, but also in Spain. Local evidence corroborates this cross border mobility. Of the 642 participants in a recent venue-based HIV prevalence study among MSM in Antwerp, Belgium, 1 in 5 men were of non-Belgian nationality, mostly Dutch [4]. These findings are in line with the mobility dynamics of European MSM. According to the EMIS final report, Spain and Germany are the most frequented countries for having sex abroad [11].

Our findings showed that the proportion of HIVpositive men was higher among sexually mobile men. This may be due to a higher number of casual sex partners and more UAI with these casual sex partners, although it cannot be established to what extent seroconversion affected the sexual behaviour of the now positive men. Sexually mobile men were also tested for HIV and STI more frequently during the last 12 months. However, mobile positive men reported higher rates of STI and substance use, and lower rates of condom use during anal sex while seroconcordant UAI with a casual partner in the last 12 months was higher compared to negative and untested MSM. This is in line with other research pointing to the fact that MSM and specifically some networks of HIV positive MSM are highly mobile and apply additional risk reduction strategies next to condom use based on their own and their partner's HIV-status, HIV treatment and viral load status [19,20]. However, these strategies do not seem to protect well against other STIs. Over the last years networks of HIV positive men have been confronted with several co-occurring epidemics of for instance Lymphogranuloma Venereum (LGV) [21] and more recently Hepatitis C [1,22-24]. Our study corroborated a link between the use of specific types of substance use, a higher number of non-steady partners and visiting patterns of specific venues where sexual contact is facilitated, which has also been established in other research [4,20,25-27]. Over one third of sexually mobile men searched for a sex partner through the Internet for their last sexual encounter abroad, confirming findings from other studies [12]. However, this study did not find an association between UAI abroad and searching for sex partners through the Internet before or during travel. An important finding in our study is that Belgian resident men, who tested HIV positive in the last 12 months, were more likely to report UAI abroad. This finding suggests that international sexual mobility may well have contributed to recent infections with HIV among European MSM. However, the data does not allow to pinpoint the exact moment of seroconversion in the last 12 months and an HIV positive diagnosis during that period may well have influenced the individual's sexual behaviour and eventually the likelihood of performing UAI.

It has to be stressed that these results cannot be generalized to all MSM, HIV negative or positive, because a majority of the study participants were recruited through specific Internet sites aiming at social and sexual networking. Being more active on these Internet sites could be an indicator of heightened sexual activity. However, the strengths of this study are its large sample size and anonymity of data collection through the Internet, which may also contribute to the validity of sensitive data [14,28]. Another limitation is that the EMIS survey did not investigate travel motivations or other more in-depth factors connected to travel behaviour.

\section{Conclusions}

The results of this EMIS study provide evidence for the role of international mobility and sexual behaviour regarding the spread of HIV and STI among MSM in Europe, while travelling abroad. As the epidemiology of HIV infection among Belgian MSM mirrors developments in its neighbouring countries, the findings underline the need for development of cross-border HIV and STI interventions with coherent messages and prevention policies for MSM. Systematic cross-border cooperation and exchange of epidemiological and behavioural data for the development of prevention activities for MSM at a regional European level should inform future prevention effort for the target population. Further research should explore in more detail the purpose of travelling and context-related characteristics that lead MSM to be sexually active while being abroad. This could inform the development of targeted prevention campaigns supporting sexually mobile MSM to reduce high risk behaviour. The presented evidence also underscores the need for multiple-behaviour interventions, targeting not only sexual behaviour but also substance use. In this context, multiple-behaviour interventions could have a greater impact on public health than single-behaviour interventions [29,30]. Further research is needed on development of effective multiple-behaviour interventions for this target group, which also must be tailored to the needs of specific subgroups such as HIV positive men [20,31-33] and HIV negative men, who are at greater risk for infections with HIV/STI [34].

\section{Competing interests}

The authors declare that they have no competing interest. 


\section{Authors' contributions}

The work presented here was carried out in collaboration between all authors. $\mathrm{W}$ and $\mathrm{HH}$ defined the research theme. WV analyzed the data. WV, $\mathrm{CN}, \mathrm{HH}$ and $\mathrm{ML}$ all interpreted the results and co-wrote the paper. All authors have contributed to, seen and approved the manuscript.

\section{Acknowledgements}

EMIS was funded by a grant of the European Commission under the EU Health Programme 2008-2013. Further funding was received from CEEISCat (Centre d'Estudis Epidemiològics sobre les ITS/HIV/SIDA de Catalunya, Spain); Department of Health for England; Maastricht University (The Netherlands); Regione del Veneto (Italy); and Robert Koch Institute (Germany). Further funding for the participation of men in specific countries was provided by: German Ministry of Health for Ukraine and Moldova; Finnish Ministry of Health for Finland; Norwegian Institute of Public Health for Norway; Swedish Board of Health and Welfare for Sweden; and Bundeszentrale für gesundheitliche Aufklärung (BZgA) for Germany. We would like to acknowledge the scientists, who organized and conducted EMIS between 2009 and 2011: Axel J. Schmidt (Project co-ordination); Ulrich Marcus (Project initiation and supervision); Peter Weatherburn (Promotion co-ordination); Ford Hickson and David Reid (Technical implementation) en the European MSM Internet Survey network. We are grateful for the support of our Belgian EMIS partners: Vladimir Martens at l'Observatoire du Sida and Sensoa VZW.

\section{Author details}

'Department of Public Health, Institute of Tropical Medicine HIV/AIDS Center (IHAC), Antwerp, Belgium. ${ }^{2}$ University College Maastricht, Maastricht University, Maastricht, The Netherlands.

Received: 24 April 2013 Accepted: 1 October 2013 Published: 18 October 2013

\section{References}

1. European Centre for Disease Prevention and Control: Techical report: STI and HIV prevention in men who have sex with men in Europe. Stockholm; 2013

2. Sasse A, Defraye A: HIV/AIDS in België, semestrieel rapport (toestand op 31 December 2011). Brussels: WIS-ISP; 2012.

3. Parsons JT, Grov C, Golub SA: Sexual compulsivity, co-occurring psychosocial health problems, and HIV risk among gay and bisexual men: Further evidence of a syndemic. Am J Public Health 2012, 102:156-162

4. Vanden Berghe W, Nostlinger C, Buve A, Beelaert G, Fransen K, Laga M: A venue-based HIV prevalence and behavioural study among men who have sex with men in Antwerp and Ghent, Flanders, Belgium, October 2009 to March 2010. Eurosurveillance 2011, 16:10-17.

5. Mirandola M, Toda CF, Krampac I, Nita I, Stanekova D, Stehlikova D, Toskin I, Gios L, Foschia JP, Breveglieri M, et al: Hiv Bio-Behavioural Survey Among Men Who Have Sex with Men in Barcelona, Bratislava, Bucharest, Ljubljana, Prague and Verona, 2008-2009. Eurosurveillance 2009, 14:22-29.

6. Herrera S, Scott D: We gotta get out of this place! Leisure travel among gay men living in a small city. Tourism Rev Int 2005, 8:249-262.

7. Casey ME: Tourist gay(ze) or transnational sex: Australian gay men's holiday desires. Leisure Stud 2009, 28:157-172.

8. Shaw G: Life style and changes in tourist consumption: The British experience. In Postmoderne Freizeitstile und Freizeiträume. Edited by Reuber P; 2005:21-45.

9. Dunne G, Flanagan S, Buckley J: Towards an understanding of international city break level. Int J Tourism Res 2010, 12:409-415.

10. Fernández Dávila $P$, Folch C, Ferrer L, Casabona J, Hickson F, Amut A, Weatherburn P, Schmidt AJ, the EMIS network: Mobile men who have sex with men: An exploration in European residents of sexual risk taking while travelling abroad. In AIDS; 2012.

11. The EMIS network: The European Men-Who-Have-Sex-With-Men Internet Survey. Findings from 38 countries. Stockholm; 2013.

12. Benotsch EG, Martin AM, Espil FM, Nettles CD, Seal DW, Pinkerton SD: Internet Use, Recreational Travel, and HIV Risk Behaviors in Men Who Have Sex With Men. J Community Health 2011, 36:398-405.

13. Benotsch EG, Seeley S, Mikytuck JJ, Pinkerton SD, Nettles CD, Ragsdale K: Substance use, medications for sexual facilitation, and sexual risk behavior among traveling men who have sex with men. Sexually Transmitted Dis 2006, 33:706-711.
14. Berg RC, Ross MW, Weatherburn P, Schmidt AJ: Structural and environmental factors are associated with internalised homonegativity in men who have sex with men: Findings from the European MSM Internet Survey (EMIS) in 38 countries. Social Sci Med 2012, 78:61-69.

15. Marcus U, Schmidt AJ, Breveglieri M, Davila PF, Ferrer L, Folch C, Hickson F Hospers HJ, Mirandola M, Reid D: S15. 3 European MSM Internet Survey (EMIS): differences in sexually transmissible infection testing in European countries. Sexually Transmitted Infect 2011, 87(1):A19.

16. Weatherburn P, Schmidt AJ, Hickson F, Reid D, Berg RC, Hospers HJ, Marcus U: the EMIS network: The European Men-who-have-sex-with-men Internet Survey (EMIS): Design and Methods. Sexuality Res Social Policy 2013, doi:10.1007/s13178-013-0119-4.

17. Kaufman MR, Fuhrel-Forbis AR, Kalichman SC, Eaton LA, Cain D, Cherry C, Pope HL: On holiday: A risk behavior profile for men who have vacationed at gay resorts. J Homosexuality 2009, 56:1134-1144.

18. Hughes HL: Gay men, travel and HIV risk. Tourism Manage 1999, 20:377-378.

19. Rosser BRS, Horvath KJ, Hatfield LA, Peterson JL, Jacoby S, Stately A: Predictors of HIV disclosure to secondary partners and sexual risk behavior among a high-risk sample of HIV-positive MSM: results from six epicenters in the US. Aids Care-Psychological and Socio-Medical Aspects of Aids/Hiv 2008, 20:925-930.

20. Kurtz SP, Buttram ME, Surratt HL, Stall RD: Resilience, syndemic factoRs, and seRosoRting behavioRs among hiv-positive and hiv-negative substance-using msm. Aids Educ Prev 2012, 24:193-205.

21. Gotz HM, Ossewaarde JM, Nieuwenhuis RF, van der Meijden WI, Dees J, Hio B: A cluster of lymphogranuloma venereum among homosexual men in Rotterdam with implications for other countries in Western Europe. Ned Tijdschr Geneeskunde 2004, 9:441-442.

22. Bottieau $E$, Apers $L$, Van Esbroeck M, Vandenbruaene M, Florence E: Hepatitis $C$ virus infection in HIV-infected men who have sex with men sustained rising incidence in Antwerp, Belgium, 2001-2009. Eurosurveillance 2010, 15:18-25.

23. Schmidt AJ, Rockstroh JK, Vogel M, Der Heiden MA, Baillot A, Krznaric I, Radun D: Trouble with bleeding: risk factors for acute hepatitis $C$ among HIV-positive gay men from GermanyGÇöa case-control study. PloS one 2011, 6: doi:10.1371/journal.pone.0017781.

24. van de Laar TJW, Matthews GV, Prins M, Danta M: Acute hepatitis C in HIVinfected men who have sex with men: an emerging sexually transmitted infection. Aids 2010, 24:1799-1812.

25. McNeely J, Silvera R, Torres K, Bernstein K, Aberg J, Gourevitch M, Daskalakis D: Current Substance Misuse and Hiv Risk Behavior Among Highly Sexually Active Men Who Have Sex with Men (Msm) Attending Commercial Sex Venues, Events and Parties (Csvep) in New York City. J Gen Internal Med 2010, 25:250.

26. Grov C: HIV risk and substance use in men who have sex with men surveyed in bathhouses, bars/clubs, and on Craigslist. org: Venue of recruitment matters. Aids and Behav 2012, 16:807-817.

27. Van Kesteren NMC, Hospers HJ, Kok G: Sexual risk behavior among HIV-positive men who have sex with men: A literature review. Patient Educ Counseling 2007, 65:5-20

28. Marcus U, Hickson F, Weatherburn P, Schmidt AJ: Prevalence of HIV among MSM in Europe: comparison of self-reported diagnoses from a large scale internet survey and existing national estimates. BMC Public Health 2012, 12: doi:10.1186/1471-2458-12-978.

29. Prochaska JJ, Spring B, Nigg CR: Multiple health behavior change research: An introduction and overview. Prev Med 2008, 46:181-188.

30. Prochaska JJ, Nigg CR, Spring B, Velicer WF, Prochaska JO: The benefits and challenges of multiple health behavior change in research and in practice. Prev Med 2010, 50:26-29.

31. Brennan DJ, Welles SL, Miner MH, Ross MW, Rosser BRS: Positive Connections Team: Hiv Treatment Optimism and Unsafe Anal Intercourse Among Hiv-Positive Men Who Have Sex with Men: Findings from the Positive Connections Study. Aids Educ Prevention 2010, 22:126-137.

32. Semple SJ, Zians J, Grant I, Patterson TL: Sexual compulsivity in a sample of HIV-positive methamphetamine-using gay and bisexual men. Aids Behav 2006, 10:587-598.

33. Wolitski RJ, Parsons JT, Gomez CA: Sums and Sumit Study Teams: Prevention with HIV-seropositive men who have sex with men - Lessons from the Seropositive Urban Men's Study (SUMS) and the Seropositive 
Urban Men's Intervention Trial (SUMIT). J Acquired Immune Deficiency Syndromes 2004, 37:S101-S109.

34. Vanden Berghe W, Nöstlinger C, Laga M: Syndemic and Other Risk Factors for Unprotected Anal Intercourse Among an Online Sample of Belgian HIV Negative Men Who have Sex with Men. AIDS Behav 2013:1-9. doi:10.1007/s10461-013-0516-y.

doi:10.1186/1471-2458-13-968

Cite this article as: Vanden Berghe et al: International mobility, sexual behaviour and HIV-related characteristics of men who have sex with men residing in Belgium. BMC Public Health 2013 13:968.

\section{Submit your next manuscript to BioMed Central and take full advantage of:}

- Convenient online submission

- Thorough peer review

- No space constraints or color figure charges

- Immediate publication on acceptance

- Inclusion in PubMed, CAS, Scopus and Google Scholar

- Research which is freely available for redistribution 